[Med. Entomol. Zool. Vol. 57 No. 1 p. 27-34 2006]

\title{
A new species of Simulium (Simulium) from Sumatra, Indonesia (Diptera: Simuliidae)
}

\author{
Hiroyuki TAKAOKA ${ }^{1)}$, Upik K. HADI ${ }^{2)}$ and Singgih H. Sigit ${ }^{2)}$ \\ 1) Department of Infectious Disease Control, Faculty of Medicine, \\ Oita University, Hasama, Yufu City, Oita, 879-5593 Japan \\ 2) Division of Parasitology and Medical Entomology, Department of Animal \\ Infectious Diseases and Veterinary Public Health, Faculty of Veterinary \\ Medicine, Bogor Agricultural University, Jl. Agatis, \\ Kampus Darmaga, Bogor, 16680 Indonesia
}

(Received: 14 November 2005; Accepted: 26 December 2005)

\begin{abstract}
A new black-fly species, Simulium (Simulium) ranauense sp. nov., is described based on the reared adults, pupae and mature larvae collected from Sumatra, Indonesia. This new species is assigned to the eximium species-group, and is very similar in the female and larva to $S$. (S.) eximium De Meijere described from Java, but is distinguished from the latter species in the male by the presence of the paired silvery iridescent dorsolateral spots on the fourth abdominal segment in addition to those on the second, fifth, sixth and seventh segments, and in the pupa by the boot-shaped cocoon with a high front wall.
\end{abstract}

Key words: Simulium, black fly, Simuliidae, Sumatra, Indonesia, new species

The eximium species-group of the subgenus Simulium (Simulium) Latreille s. str. defined by Takaoka and Davies (1996) is composed of three known species, $S$. (S.) eximium De Meijere, S. (S.) thienemanni Edwards and S. (S.) upikae Takaoka and Davies, all of which were originally reported from Java (De Meijere, 1913; Edwards, 1934; Takaoka and Davies, 1996). During our surveys in 1991-1994, two species of this species-group were collected, one from Flores and the other from Sumatra, of which the former was identified as S. (S.) upikae (Takaoka et al., 2006), and the latter was reported as $S$. (S.) sp. nr. eximium (Takaoka et al., 2000).

In this paper, the latter species is described as new to science, based on the reared adults, pupae and mature larvae collected from Sumatra.

The terms for morphological features used here follow those of Takaoka (2003). Holotype and paratype specimens of the new species are deposited at the Depart- ment of Infectious Disease Control, Oita University, Oita, Japan.

\section{Simulium (Simulium) ranauense sp. nov.}

Simulium (Simulium) sp. nr. eximium; Takaoka et al. 2000: 165.

DESCRIPTION. Female. Body length 3.5 mm. Head. Narrower than width of thorax. Frons black, shiny, thinly grey pruinose, with several dark stout hairs along lateral margins; frontal ratio $1.3: 1.0: 1.1-1.2$; frons-head ratio $1.0: 3.7-4.1$. Fronto-ocular area (Fig. 1A) well developed, directed laterally and a little upwardly. Clypeus black, slightly shiny, grey pruinose, moderately covered with dark stout hairs; when illuminated, clypeus silvery iridescent. Labrum 0.6-0.7 times as long as clypeus. Antenna composed of $2+9$ segments, dark brown except scape and base of pedicel yellow in posterior view, and dark brown except scape, pedicel and 1st to 3rd flagellar segments yellowish in anterior view. Maxillary palp composed of 5 segments, proportional lengths 


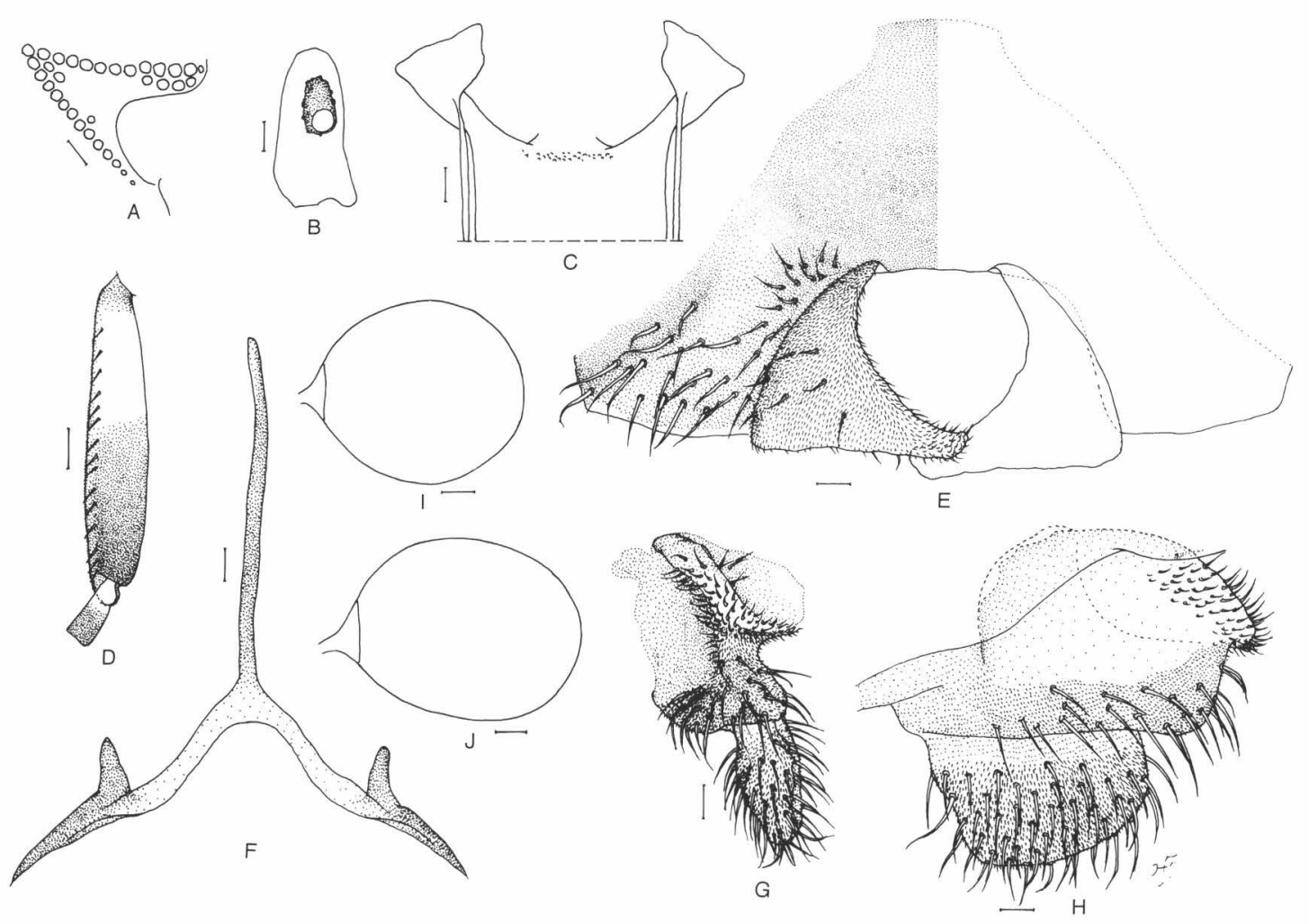

Fig. 1. Female of Simulium (Simulium) ranauense sp. nov. A, fronto-ocular area (right side); B, 3rd segment of maxillary palp with sensory vesicle (right side, front view); C, cibarium; D, basitarsus and 2nd tarsal segment of hind leg showing calcipala and pedisulcus (left side, outer view); E, 8th sternite and ovipositor valves in situ (ventral view); F, genital fork (ventral view); G and H, paraprocts and cerci (right side; G, ventral view; H, outer view); I and J, spermathecae. Scale bars. $0.1 \mathrm{~mm}$ for D; 0.03 $\mathrm{mm}$ for $\mathrm{A}$ and $\mathrm{B} ; 0.02 \mathrm{~mm}$ for $\mathrm{C}$ and $\mathrm{E}-\mathrm{J}$.

of $3 \mathrm{rd}, 4$ th, and 5 th segments $1.0: 1.2: 2.5-2.6$; 3rd segment (Fig. 1B) not enlarged; sensory vesicle (Fig. 1B) of medium size, oblong, 0.340.36 times as long as $3 \mathrm{rd}$ segment, with large or very large round opening apically. Maxillary lacinia with 13-15 inner and 13-15 outer teeth. Mandible with 21-28 inner and 11-13 outer teeth. Cibarium (Fig. 1C) with 20-26 minute tubercles. Thorax. Scutum brownish-black, with distinct patterns formed by pruinose and non-pruinose areas; when illuminated anterodorsally and viewed dorsally, scutum widely whitish-grey pruinose with 5 rather broad longitudinal non-pruinose dark vittae (1 medial, 2 submedial and 2 sublateral vittae), and in addition, scutum with pair of whitish pruinose spots subanteriorly; when illuminated posterodorsally and viewed dorsally, scutum with reversed pattern with 4 nonpruinose longitudinal vittae; scutum densely covered with yellow recumbent short hairs and dark similar hairs interspersed with dark long upright hairs on prescutellar area. Scutellum dark brown, with yellow recumbent short hairs and dark long upright hairs. Postnotum dark brown, shiny, whitish pruinose, iridescent when illuminated at certain angle of light, bare. Pleural membrane bare. Katepisternum longer than deep, bare, whitish-grey pruinose. Legs. Almost brownish-black to black except fore coxa, hind trochanter, a little less than basal $1 / 2$ of hind basitarsus and basal $2 / 5$ of hind 2nd tarsal segment yellowish-white, and base of hind tibia dark yellow to light brown; mid and hind tibiae white sheeny basally on posterior surface when illuminated at certain angle of light. Fore tarsus with thick dorsal hair crest; basitarsus much dilated, 4.3-4.4 times as long as its greatest width. Hind basitarsus (Fig. 1D) slightly widened from base toward apical 
$2 / 5$ or more, then narrowed apically, $4.9-5.1$ times as long as its greatest width, $0.72-0.83$ and $0.72-0.79$ times as wide as greatest widths of hind tibia and femur, respectively; calcipala short, about 0.7 times as long as width at base; pedisulcus distinct; all tarsal claws simple. Wing. Length $2.7 \mathrm{~mm}$. Costa with spinules and hairs. Subcosta haired except near base bare. Basal section of vein $\mathrm{R}$ fully haired; $\mathrm{R}_{1}$ with spinules and hairs; $R_{2}$ with hairs only. Hairs at base of stem vein dark brown. Basal cell absent. Abdomen. Basal scale brownish-black, with fringe of dark hairs; 2nd segment pale on anterior $2 / 5-1 / 2$ and brownish-black on posterior $1 / 2-3 / 5$, with pair of large whitish iridescent dorsolateral spots broadly connected to each other medially; dorsal surface of segments 3-9 brownish-black, and with dark hairs; tergites 6 -9 shiny. Ventral surface of abdominal segment 7 with very large sternal plate medially, densely covered with dark stout hairs except anterior $1 / 3$ bare. Genitalia. Sternite 8 (Fig. 1E) well sclerotized, with anterior expansion medially, bare medially but with 26-36 hairs on each side (smaller and shorter hairs submedially, longer and stouter ones laterally); ovipositor valves (Fig. 1E) triangular, flap-like, protruding ventrally, then curved inward and meeting each other apically in middle, thin, membranous, pale brownish, covered with 7 or 8 short hairs as well as numerous microsetae; inner margin deeply concave, rather widely folded back throughout its length, and moderately covered with microsetae on this folded area as well as on outer surface. Genital fork (Fig. 1F) of inverted-Y form; stem slender and well sclerotized; arms slender, each with strongly sclerotized lateral ridge having distinct projection directed anterodorsally. Paraproct in ventral view (Fig. 1G) widened, 0.7 times as wide as long, well sclerotized basally, having medial projection directed ventrally, with its apex not pigmented, rounded, with numerous colorless setae; anteromedial surface of paraproct moderately sclerotized, gently sloped, with 6-9 sensilla; paraproct in lateral view (Fig. $1 \mathrm{H})$ with outer surface widely depressed, moderately sclerotized, smooth, lacking hairs (except 1 stout hair in left paraproct of 1 female) and microsetae except posterior $1 / 4$ covered with 16-20 stout hairs and numerous microsetae. Cercus in lateral view (Fig. $1 \mathrm{H}$ ) nearly rectangular, 0.51-0.57 times as long as wide, cov- ered with numerous stout hairs. Spermatheca globular or ovoidal (Fig. 1I, J), well sclerotized except duct and small area of juncture to duct unsclerotized, with faint reticulate surface patterns; minute internal setae present; both accessory ducts subequal in diameter to each other, and somewhat thicker than that of main duct.

Male. Body length $3.2-3.5 \mathrm{~mm}$. Head. As wide as thorax. Upper eye consisting of large facets in 17-19 horizontal and 17 or 18 vertical rows. Clypeus black, whitish-grey pruinose, iridescent when illuminated, moderately covered with dark brown long hairs except median portion widely bare. Antenna composed of $2+9$ segments, dark brown except base of 1st flagellar segment pale; 1st flagellar segment elongate, about 1.5 times as long as 2nd one. Maxillary palp composed of 5 segments, proportional lengths of $3 \mathrm{rd}, 4$ th, and 5 th segments $1.0: 1.2: 2.8$; 3rd segment (Fig. 2A) of normal size, with small ellipsoidal sensory vesicle (Fig. 2A) about 0.2 times as long as 3rd segment. Thorax. Scutum brownish-black, with white pruinose and iridescent patterns differing with angles of light: when illuminated anterodorsally and viewed dorsally, scutum with white iridescent transverse band along anterior margin, somewhat wide in middle and narrow on each side, and with pair of narrow rectangular white spots subanteriorly widely spaced in middle; when illuminated posterodorsally and viewed dorsally, scutum with large transverse white band on posterior $2 / 5$ including entire prescutellar area; when illuminated anterolaterally and viewed laterally, scutum on each side has large white anterior spot including subanterior narrow spot which extends posteriorly along lateral border and continues to posterior large white band; scutum uniformly and densely covered with golden-yellow recumbent fine hairs interspersed with dark similar hairs near anterior border and dark long upright hairs on prescutellar area. Scutellum brownish-black, whitish pruinose, with several dark long upright hairs and golden-yellow short hairs. Postnotum, pleural membrane and katepisternum similar to those of female. Legs. Almost brownish-black to black except fore coxa, hind trochanter, basal $2 / 5$ of hind basitarsus and basal $1 / 3$ of hind 2 nd tarsal segment whitish-yellow, and base of mid basitarsus and base of hind tibia dark yellow to 


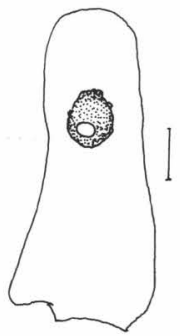

A

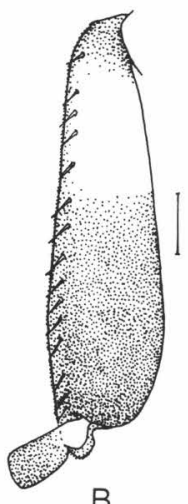

B
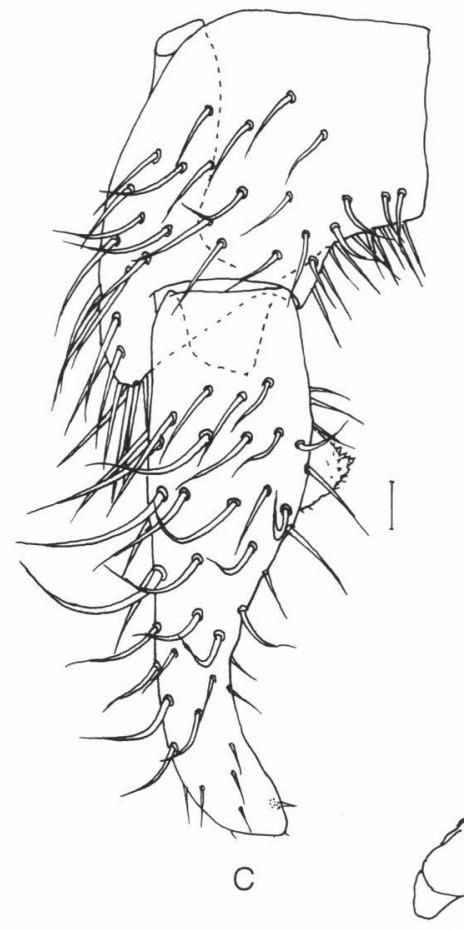
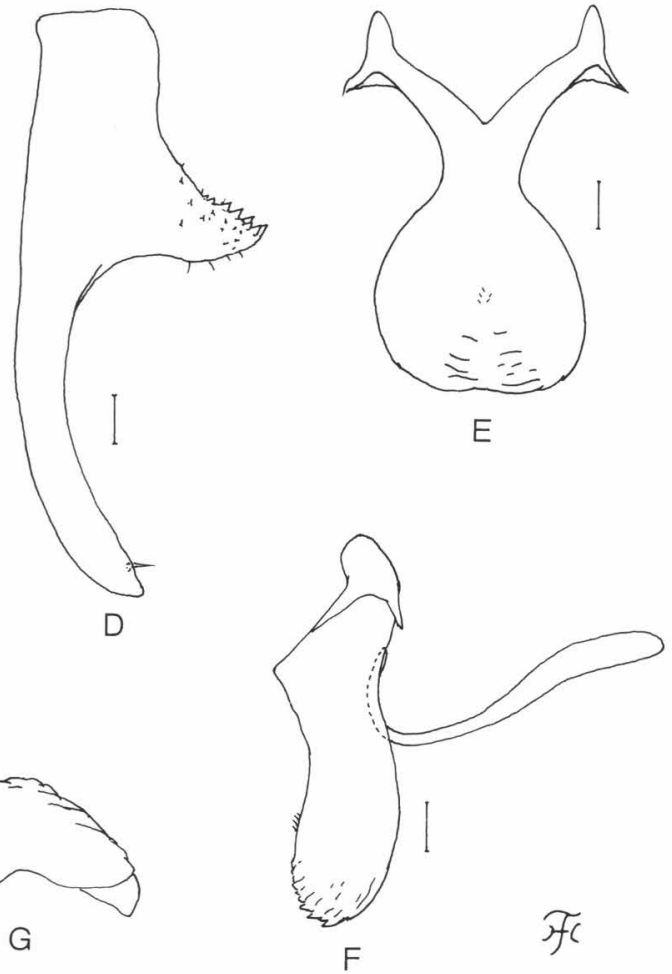

Fig. 2. Male of Simulium (Simulium) ranauense sp. nov. A, 3rd segment of maxillary palp with sensory vesicle (right side, front view); B, basitarsus and 2nd tarsal segment of hind leg showing calcipala and pedisulcus (left side, outer view); C, coxite and style in situ (right side, ventral view); D, style showing basal protuberance (right side, medial view); E and G, ventral plates (E, ventral view; G, end view); F, ventral plate and median sclerite (lateral view). Scale bars. $0.1 \mathrm{~mm}$ for B; $0.02 \mathrm{~mm}$ for A and C-G.

light brown; mid and hind tibiae white sheeny basally on posterior surface when illuminated at certain angle of light. Fore tarsus with thick dorsal hair crest; basitarsus somewhat dilated, about 5.1 times as long as its greatest width. Hind basitarsus (Fig. 2B) enlarged, wedgeshaped, 3.7 times as long as its greatest width, 0.89 and $0.97-1.01$ times as wide as greatest widths of hind tibia and femur, respectively; calcipala small, about 0.9 times as long as wide; pedisulcus distinct. Wing. Length about 2.5 $\mathrm{mm}$; other characters as in female except subcosta and basal portion of vein $\mathrm{R}$ entirely bare. Abdomen. Basal scale blackish, with fringe of dark long hairs. Dorsal surface of abdomen black, with dark hairs; segments 2 and 4-7 each with pair of silvery iridescent dorsolateral spots, connected broadly on segment 2 and narrowly on other segments to each other medially; tergites of segments 3,8 and 9 also shiny at certain angle of light, and that of segment 8 appears to have small silvery irides- cent lateral area on each side in some males. Genitalia. Coxite in ventral view (Fig. 2C) 1.2 times as long as wide, somewhat protruding posterolaterally beyond anterior margin of style. Style in ventral view (Fig. 2 C) elongate, about 1.4 times as long as coxite, nearly parallel-sided on basal $1 / 3$, abruptly narrowed toward apical $1 / 3$, then nearly parallel-sided on apical $1 / 3$, with inner margin deeply concave on apical $2 / 3$, and with very slender apical spine subapically; style in medial view (Fig. 2D) flattened ventrodorsally, with prominent subbasal protuberance pointed dorsally and bearing several cone-shaped spines on tip and anterior surface. Ventral plate in ventral view (Fig. $2 \mathrm{E})$ with body nearly pear-shaped, irregularly furrowed on ventroposterior surface, and with a few to several minute setae medially on ventral surface; basal arms short, stout, diverging from each other; ventral plate in lateral view (Fig. 2F) with body slightly curved ventrally and with dentate posterior margin; ventral 
plate in end view (Fig. 2G) with body equilaterally triangular in shape, bare, with several furrows on posterolateral margins. Median sclerite wide, thin, plate-like. Paramere with several parameral hooks. Aedeagal membrane moderately covered with minute setae, without sclerotized dorsal plate. Ventral surface of 10th abdominal segment without any distinct hairs. Cercus rounded, with 8 or 9 distinct hairs.

Pupa. Body length (excluding gill filaments) about $4.0 \mathrm{~mm}$. Head. Integument yellow to yellowish-brown, densely covered with round tubercles, of which those on frons are somewhat larger than those on face and antennal sheaths and bear several minute projections on their surface (Fig. 3A): frons with pair of simple and bifid short trichomes (Fig. 3B) on each side; face with 1 bifid medium-long trichome (Fig. 3 C) on each side. Thorax. Integument yellow to yellowish-brown, with anterior pair of rugose swellings (Fig. 3D), moderately covered with large tubercles with several minute projections on their surface (Fig. 3E) on mediodorsal surface of anterior $1 / 2$, densely covered with similar but somewhat smaller ones on anterior swellings, moderately covered with small round or cone-shaped tubercles without secondary projections on lateral and posterodorsal surfaces; thorax with 3 pairs of

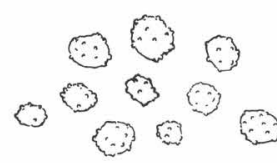

A

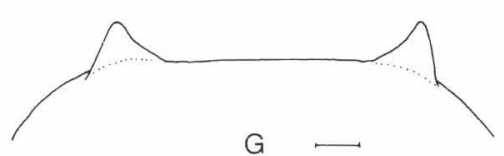

G

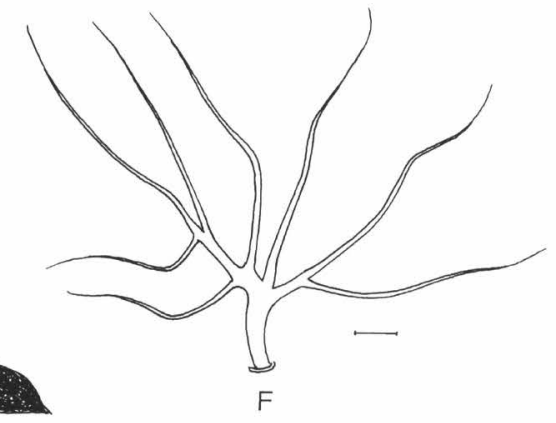

$\mathrm{H}$

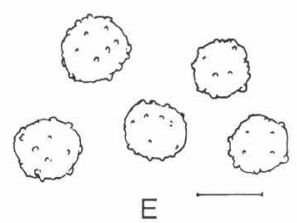

E

B

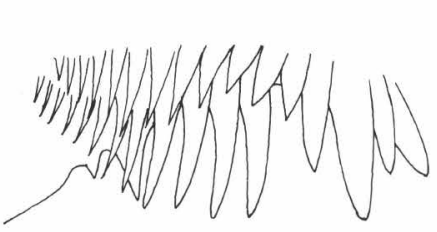

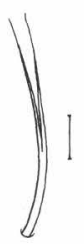

C

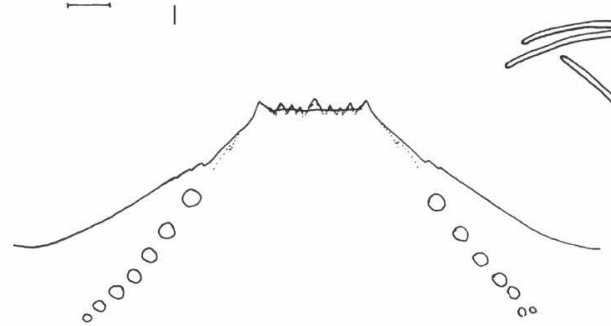

FC

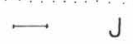

Fig. 3. Pupa and larva of Simulium (Simulium) ranauense sp. nov. A-H, pupa. I and J, larva. A, tubercles on frons; B, facial trichomes; $\mathrm{C}$, frontal trichome; $\mathrm{D}$, integument of anterior portion of thorax with rugose swelling on dorsal surface (arrow) and with gill filaments (left side; outer view); E, large tubercles on dorsal surface of thorax; F, fan-like trichome on dorsomedial surface; G, terminal hooks (end view); H, cocoon (lateral view); I, apex of mandible; J, hypostoma. Scale bars. $1.0 \mathrm{~mm}$ for $\mathrm{H}$; $0.1 \mathrm{~mm}$ for D; $0.02 \mathrm{~mm}$ for B, C, F, G and J; $0.01 \mathrm{~mm}$ for A, E and I. 
branched fan-like very long trichomes split into 6-9 branches (Fig. 3F) mediodorsally, 2 pairs of similar branched fan-like very long trichomes anterolaterally, 1 pair of long trichomes split into $2-5$ branches posterolaterally, and 3 pairs of trichomes ( 1 long simple or split into 2-4 branches, 1 long with $3-5$ branches, 1 medium-long with 3-7 branches) ventrolaterally. Gill (Fig. 3D) with 10 slender thread-like filaments in pairs, all subequal in length and thickness (though 1 or both of 2 filaments of lowest pair apparently shorter than other filaments in a few pupae); all filaments much shorter than pupa, usually not extending beyond opening of cocoon, gradually tapered toward apex; cuticular surface with very distinct annular ridges and furrows throughout their length forming well defined reticulate pattern, covered with minute tubercles of different sizes, larger ones on ridges and smaller ones on interridge spaces. Abdomen. Dorsally, segment 1 light to medium brown and segments 2-9 almost transparent to light brown; segment 1 with 1 simple or bifid slender medium-long hair-like seta on each side; segment 2 with 1 simple or bifid slender mediumlong hair-like seta and 5 simple or bifid short spinous setae on each side; segments 3 and 4 each with 4 hooked spines and 1 simple or bifid short spinous seta on each side; segments $5^{-7}$ bare; segments 8 and 9 each with comb-like groups of minute spines but lacking spinecombs; segment 9 with pair of distinct coneshaped terminal hooks (Fig. 3G). Ventrally, all segments transparent to light yellowishbrown; segments 3-8 each with comb-like groups of minute spines on each side; segment
4 with 1 simple medium-long seta and 3 simple short setae on each side; segment 5 with pair of simple or bifid hooks submedially and 1 simple short seta on each side; segment 6 and 7 each with pair of bifid to quadrifid inner and simple or bifid outer hooks widely spaced and 1 simple short seta on each side. Grapnel-like hooklets absent. Cocoon (Fig. 3H). Boot-shaped, with rather high front wall (1.2-2.5 $\mathrm{mm}$ high), somewhat loosely woven with flat coarse fibres forming several small open spaces near opening; posterior $1 / 2$ of ventral surface with floor; $5.2-5.8 \mathrm{~mm}$ long by $2.0 \mathrm{~mm}$ wide.

Mature larva. Body length $7.2-8.5 \mathrm{~mm}$. Body color greyish-brown to dark brown. Cephalic apotome usually yellow or dark yellow on anterior $1 / 2$, light brown to dark brown on posterior $1 / 2$, with narrow portion along posterior border darkest; anterior spot of mediolongitudinal spots positive in lighter ground color, and posterior spot of mediolongitudinal spots as well as mediolateral spots also positive in some larvae (Fig. 4A), but almost merged into dark ground color in others; posterolateral spots usually merged into dark ground color or faintly negative depending upon extent of darkness of ground color; lateral surface of head capsule darkened except eye-spot region and anteroventral area paler, with spots below and behind eye-spot region merged into dark ground color or faintly negative in some larvae (Fig. 4B), or almost entirely darkened except eye-spot region in others; ventral surface of head capsule also variable in color: e.g., darkened on posterior $1 / 2$ and yellow on anterior $1 / 2$ (Fig. 4 C) in some larvae, and almost darkened except
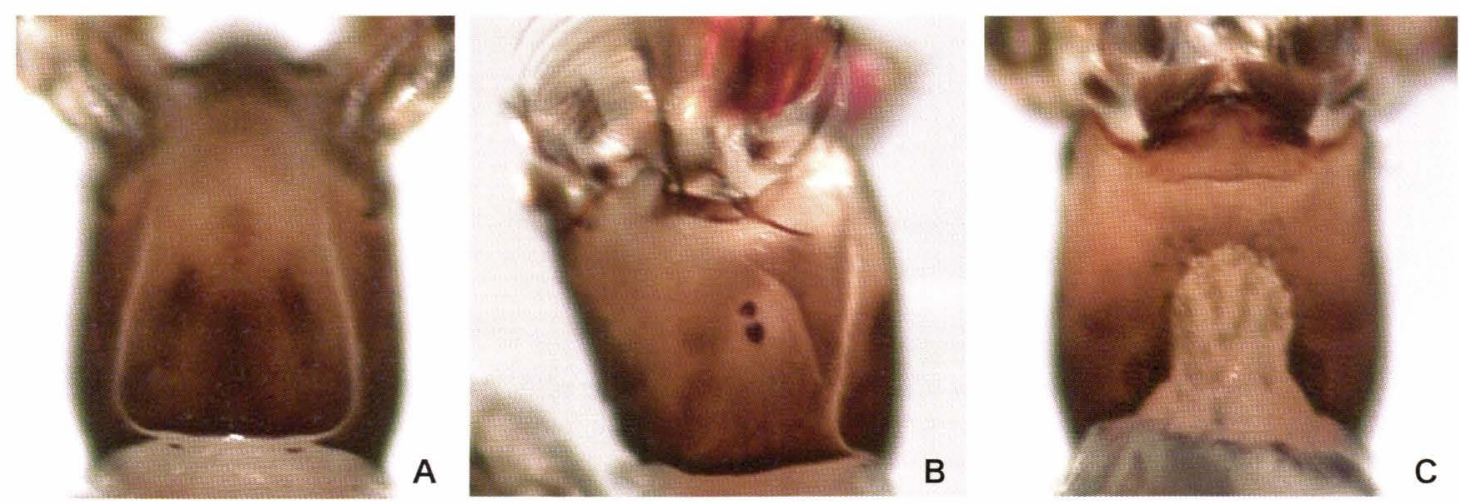

Fig. 4. Larval head capsules of Simulium (Simulium) ranauense sp. nov. A, dorsal view; B, lateral view; C, ventral view. 
narrow yellow area along posterior margin of hypostoma in others. Cervical sclerite composed of 2 dark small elliptical pieces, not fused to occiput, very widely separated medially from each other. Antenna composed of 3 segments and apical sensillum, longer than stem of labral fan; proportional lengths of 1st, 2nd, and 3rd segments $1.0: 1.3: 0.5$. Labral fan with 38-42 main rays. Mandible (Fig. 3I) with mandibular serrations composed of 2 teeth (1 large, 1 small); large tooth at obtuse angle to mandible on apical side; supernumerary serrations absent; 2 nd and 3 rd comb-teeth subequal in length, shorter than 1st tooth. Hypostoma (Fig. 3J) with 9 anterior teeth, of which median and corner teeth prominent; lateral margins weakly serrate apically; 7 or 8 hypostomal bristles diverging posteriorly from lateral border on each side. Postgenal cleft (Fig. 4C) mediumlong, bullet-shaped, rounded apically, 1.9-2.5 times as long as postgenal bridge. Thoracic cuticle almost bare. Abdominal cuticle almost bare except each side of anal sclerite covered with short colorless setae. Rectal scales absent. Rectal organ of compound lobes, each with 1317 finger-like secondary lobules. Anal sclerite $\mathrm{X}$-shaped, with broadened anterior arms about 0.6 times as long as posterior ones. Last abdominal segment bulged laterally, lacking ventral papillae. Posterior circlet with 164-192 rows of hooklets with up to 24 hooklets per row.

TYPE SPECIMENS. Holotype female (with associated pupal exuviae and cocoon), reared from pupa, collected from a creek (width 2.0-3.0 m, water temperature $24.0^{\circ} \mathrm{C}$, partially shaded, altitude ca. $500 \mathrm{~m}$ ) flowing down to the Lake Ranau, at Tanjungjati, along the road between Simpangsender and Liwa, Bengkulu, Sumatra, Indonesia, 29. VII. 1992, by H. Takaoka. Paratypes: 5 females, 5 males and 5 mature larvae, same data and date as those of holotype; 1 female, 2 males, 2 pupae, 5 mature larvae, collected from a river (width ca. $10 \mathrm{~m}$, water temperature $20.0^{\circ} \mathrm{C}$, exposed to sun, altitude $560 \mathrm{~m}$ ) at Airmancuur, along the road from Kayutanam to Padangpanjang, Bukittinggi, West Sumatra, Sumatra, 14. VIII. 1994; 4 females, 8 males, 4 pupae and 8 mature larvae, collected from a river (width 10-15 $\mathrm{m}$, water temperature $23.0^{\circ} \mathrm{C}$, partially shaded, altitude ca. $340 \mathrm{~m}$ ) moderately or rapidly flowing in a natural forest in Pasaman, half way between Bonjol and Lubuksikaping, Bukittinggi, West Sumatra, Sumatra; 18.VIII.1994.

ECOLOGICAL NOTES. The pupae and larvae of this species were collected on trailing grasses, plastic sheets and stones in the rapids of fast-flowing streams. Associated species were S. (Gomphostilbia) sundaicum Edwards, S. (Nevermannia) feuerborni Edwards, S. (S.) iridescens De Meijere, $S$. (S.) nobile De Meijere and $S$. (S.) argyrocinctum De Meijere.

\section{DISTRIBUTION. Sumatra.}

ETYMOLOGY. The species ranauense refers to the lake Ranau, near the type locality of this new species.

REMARKS. Simulium (S.) ranauense sp. nov. is very similar to $S$. (S.) eximium described from Java (De Meijere, 1913; Edwards, 1934) in many features including the female and male genitalia, the arrangement of the pupal gill, and the larval postgenal cleft. However, this new species is distinguished from the latter in the male by the presence of the paired silvery iridescent dorsolateral spots on the fourth abdominal segment in addition to those on the fifth to seventh abdominal segments (cf., similar iridescent spots only on the fifth to seventh abdominal segments in $S$. (S.) eximium), in the pupa by the bootshaped cocoon with a high front wall and small open spaces anteriorly (cf., the front wall is of moderate height and the open spaces are relatively large in $S$. (S.) eximium), and in the larva by the labral fan with 38-42 main rays (cf., about 60 main rays in $S$. (S.) eximium).

It should be noted that this new species has been proven cytotaxonomically to be distinct from $S$. (S.) eximium by Hadi et al. (1996). 


\section{ACKNOWLEDGEMENTS}

We would like to thank Dr. I. Miyagi, Professor Emeritus, University of the Ryukyus, who provided us the opportunity to take part in his project "Survey on Biogeography and Coevolution of Vectors, Parasites and Hosts in Indonesia" carried out during 1991-1994, by a Grant-in-Aid for the International Scientific Research Programme from the Ministry of Education, Science and Culture, Japan (No. 03041065 and No. 06041090), and under the permission and support of the Indonesian Institute of Science.

Our appreciation goes to Dr. Yasushi Otsuka, Oita University, for his kind help in taking photographs of larvae and preparing Fig. 4.

\section{REFERENCES}

De Meijere, J.C.H. 1913. Studien über Südostasiatische Dipteren VII. Tijdschr. Entomol., 56:
317-354 (Simuliidae pp. 330-333).

Edwards, F. W. 1934. The Simuliidae (Diptera) of Java and Sumatra. Arch. f. Hydrobiol., 13, Suppl. "Tropische Binnengewässer", 5: 92-138.

Hadi, U.K., Takaoka, H., Kondo, K. and Hirai, H. 1996. Larval polytene chromosomes of Simulium (Simulium) eximium (Diptera: Simuliidae) from Java and Sumatra, Indonesia. Med. Entomol. Zool., 47: 139-144.

Takaoka, H. 2003. The Black Flies (Diptera: Simuliidae) of Sulawesi, Maluku and Irian Jaya. xxii + 581 pp., Kyushu University Press, Fukuoka.

Takaoka, H. and Davies, D. M. 1996. The Black Flies (Diptera: Simuliidae) of Java, Indonesia. viii +81 pp., Bishop Mus, Bull. Entomol., 6, Bishop Museum Press, Hawaii.

Takaoka, H., Hadi, U. K. and Sigit, S. H. 2006. The black flies (Diptera: Simuliidae) of Flores and Timor, Indonesia. Med. Entomol. Zool., 57: in press. Takaoka, H., Yunus, M., Hadi, U. K., Sigit, S. H. and Miyagi, I. 2000. Preliminary report of faunistic surveys on black flies (Diptera: Simuliidae) in Sumatra, Indonesia. Jpn. J. Trop. Med. Hyg., 28: 157166. 